\title{
Alleviation of Dendrite Formation on Zinc Anodes via Electrolyte Additives
}

Xiaoxia Guo, ${ }^{[a]}$ Zhenyu Zhang, ${ }^{[b]}$ Jianwei Li, ${ }^{[a]}$ Ningjing Luo, ${ }^{[d]}$ Guo-Liang Chai, ${ }^{[d]}$ Thomas S. Miller, ${ }^{[b]}$ Feili Lai, ${ }^{[e]}$ Paul Shearing, ${ }^{[b]}$ Dan J.L. Brett, ${ }^{[b]}$ Daliang Han, ${ }^{[f]}$ Zhe Weng, ${ }^{[f]}$ Guanjie He ${ }^{[a b c]}$ *and Ivan P. Parkin $^{[a] *}$

[a] Department of Chemistry, University College London, Christopher Ingold Laboratory, 20 Gordon Street, London WC1H 0AJ, U.K.

[b] Department of Chemical Engineering, UCL; Electrochemical Innovation Lab, London WC1E 7JE, U.K.

[c] School of Chemistry, University of Lincoln; Joseph Banks Laboratories, Green Lane, Lincoln, LN6 7DL, U.K.

[d] State Key Laboratory of Structural Chemistry; Fujian Institute of Research on the Structure of Matter; Chinese Academy of Sciences (CAS), Fuzhou, 350002 Fujian, P. R. China.

[e] Department of Chemistry, KU Leuven; Celestijnenlaan 200F, Leuven 3001, Belgium

[f] Nanoyang Group, State Key Laboratory of Chemical Engineering, School of Chemical Engineering and Technology, Tianjin University, Tianjin 300350, China.

*Corresponding Author : g.he@ucl.ac.uk;

i.p.parkin@ucl.ac.uk

Abstract: Zinc anode-based batteries have been widely studied due to their low cost, high capacity and high energy density. However, the formation of dendrites on the zinc anode during cycling severely affects the stability and safety of this type of battery. In this work, a series of electrolyte additives with potential to counter this problem were studied. We found that lithium chloride $(\mathrm{LiCl})$ additive can suppress the growth of dendrites and stabilize the $\mathrm{Zn}$ metal anode, on which the cations $\left(\mathrm{Li}^{+}\right)$preferentially form $\mathrm{Li}_{2} \mathrm{O} / \mathrm{Li}_{2} \mathrm{CO}_{3}$ upon the $\mathrm{Zn}$ surface and provide a shielding effect to suppress dendritic deposition, while a moderate amount of anions $\left(\mathrm{Cl}^{-}\right)$decrease the $\mathrm{Zn}$ polarization and facilitate ion transport. Asymmetric cells with $\mathrm{LiCl}$ additives in the electrolyte showed notably higher stability during the long cycling process. 
The demand for electrical energy in modern society is growing. ${ }^{1}$ Cheap, reliable and eco-friendly electrical energy storage (EES) will play a key role in supplying this demand without simultaneously increasing pollution or driving climate change. An ideal EES device should have a high capacity, be able to charge/discharge quickly, be safe, be environmentally benign, and come at a low cost. Among the available EES technologies, rechargeable metal batteries are promising in terms of their energy density, scalability and flexibility. ${ }^{2}$ Zinc-based batteries, which use zinc as the anode, include zinc-air batteries and zinc-based flow batteries have been studied widely due to their versatility. ${ }^{3-7}$ Zinc has a relatively high capacity density $\left(5855 \mathrm{mAh} \mathrm{cm}^{-3}\right)$, low cost, operational safety and is relatively non-toxic compared with other metal anodes like $\mathrm{Li}$ and $\mathrm{Na}^{8-10}$ Also, compared with the potential of a standard hydrogen electrode (SHE), the redox potential of $\mathrm{Zn} / \mathrm{Zn}^{2+}$ is $-0.763 \mathrm{~V}$, which makes it suitable for being applied as a metal anode in aqueous electrolytes. ${ }^{11}$ Therefore, batteries with $\mathrm{Zn}$ anodes are easy to manufacture with low environmental and economic impacts. ${ }^{5,12}$ These advantages make the development of zinc anode based batteries of global importance. ${ }^{13-15}$

Unfortunately, one major problem must be overcome before zinc anode batteries can be widely utilised, the formation of zinc dendrites during cycling. Zinc dendrites form during the deposition and dissolution of zinc anodes. However, they can severely affect the stability and longevity of zinc-based batteries as the growing dendrites can penetrate the separator and lead to direct contact between the anode and the cathode, causing a short circuit and battery failure. Recently, many approaches have been adopted to improve the reversibility of the $\mathrm{Zn}$ plating-striping process and extend the cycle life of $\mathrm{Zn}$ metal electrodes, such as the introduction of additives into electrolytes and electrodes, ${ }^{10,16-19}$ modification of the intrinsic structures of zinc-based anodes, ${ }^{7,20,21}$ better design of separators ${ }^{22,23}$ and optimization of the intrinsic properties of the electrolytes. ${ }^{5,24-26}$ Among them, electrolyte modification is one of the most facile and effective methods because of its compatibility to existing battery fabrication methods.

$\mathrm{Zn}$ anode batteries use aqueous electrolytes as they are typically safer, cheaper and easier to use for battery assembly than non-aqueous ones. ${ }^{27,28}$ Moreover, higher ionic conductivity is typically provided by the 
aqueous electrolyte, which facilitates high rate performance. ${ }^{29}$ Alkaline electrolytes are not ideal as they tend to cause the growth of dendrites mainly composed of non-conductive $\mathrm{ZnO}$, resulting in severe capacity fading and low coulombic efficiency (CE). ${ }^{30-32}$ Strong acid electrolytes are not ideal either, as they result in poor long-term reliability as they can cause the corrosion of current collectors and $\mathrm{Zn}$ anodes. Therefore, neutral or weak acidic electrolytes are most promising for $\mathrm{Zn}$ anode batteries. $\mathrm{ZnSO}_{4}$ is widely used in $\mathrm{Zn}$ ion batteries (ZIBs) owing to its low cost and stability, and remarkable performances have been achieved based on its aqueous electrolyte. However, due to problems associated with the formation of $\mathrm{Zn}_{4}(\mathrm{OH})_{6} \mathrm{SO}_{4} \cdot \mathrm{nH}_{2} \mathrm{O}$ (ZHS, a non-conductive compound), this type of electrolyte seems not perfect or irreplaceable. ${ }^{33,34}$ Additives including polymers, organic molecules, and metal ions ${ }^{35-37}$ have been shown to significantly change the properties of electrochemical reactions. It has been demonstrated that $\mathrm{Mn}^{2+}$ in the electrolyte not only avoids the dissolution of $\mathrm{MnO}_{2}$, but also effectively improves the $\mathrm{CE}$ of the $\mathrm{Zn}$ electrode, and thus enhance the cyclability of $\mathrm{MnO}_{2}{ }^{6}$ The minimum additional amount of $0.029 \mathrm{~g} \mathrm{~L}^{-1}$ tetrabutylammonium sulfate $\left(\mathrm{TBA}_{2} \mathrm{SO}_{4}\right)$, as a cationic surfactant-type electrolyte additive in $\mathrm{Zn}$-ion batteries, which can induce the uniform $\mathrm{Zn}$ deposition in both electrode preparation and the battery charge/discharge process has been proposed. ${ }^{38}$ Typically, introducing a protection layer, such as an ultrathin $\mathrm{TiO}_{2}$ film ${ }^{39}$ and a nanoporous $\mathrm{CaCO}_{3}$ coating ${ }^{40}$, has been revealed as an effective strategy to impede the dendrite growth, leading to long life aqueous ZIBs. Three-dimensional (3D) Zn architecture has been also shown to be able to eliminate dendrite formation by minimizing the shape change ${ }^{20,41}$. Nevertheless, despite the initial success, these strategies all faces large technical hurdles for practical and scalable fabrications.

Herein, we report a new electrolyte additive, lithium chloride $(\mathrm{LiCl})$, for stabilizing $\mathrm{Zn}$ metal electrodes in a synergistic manner. We find that the cation $\left(\mathrm{Li}^{+}\right)$and anion $\left(\mathrm{Cl}^{-}\right)$cooperate to improve the efficiency, cycling life and stability of $\mathrm{Zn}$ ion batteries. Compared with other additives, the cost of $\mathrm{LiCl}$ is low. $\mathrm{Zn}$ dendrite formation can be suppressed successfully by introducing a simple in situ growth of protective layer on the $\mathrm{Zn}$ surface, the cation $\left(\mathrm{Li}^{+}\right)$provides an oxide layer shielding effect, whereas the anion $\left(\mathrm{Cl}^{-}\right)$ 
helps to decrease the polarization and increase the ion transport. The function of different anions $\left(\mathrm{SO}_{4}{ }^{2-}\right.$, $\mathrm{NO}_{3}^{-}$) is also investigated and discussed. Finally, two prototype cells with high CE, large capacity and long-term cycling stability are achieved.

Swagelok cells were assembled and were charged/discharged for 500 cycles ( $20 \mathrm{~min} / \mathrm{cycle}$ ) at a current density of $0.2 \mathrm{~mA} \mathrm{~cm}^{-2}$ (total time $170 \mathrm{~h}$ ) to evaluate the $\mathrm{Zn}$ dissolution/deposition behaviour of $\mathrm{Zn}$ electrodes in the different electrolytes. Figure 1a shows the voltage-time profiles of $\mathrm{Zn}-\mathrm{Zn}$ cells in pure $3 \mathrm{~m} \mathrm{ZnSO}_{4}$ and $3 \mathrm{~m} \mathrm{ZnSO}_{4}$ with $2 \mathrm{~m} \mathrm{LiCl}$ as an additive. As shown by their profiles at the first cycle and the $500^{\text {th }}$ cycle (inset of Figure 1a), the overpotential of $\mathrm{Zn}$ deposition reduces from 220 to $38 \mathrm{mV}$ with a $2 \mathrm{~m} \mathrm{LiCl}$ electrolyte additive. More importantly, it can be seen that the potential of the $500^{\text {th }}$ cycle is similar to that of the $1^{\text {st }}$ cycle. This indicates the additive was not harmful to the cycling life, it has a very stable redox behavior even over a long cycling duration. The overpotentials of the redox reaction are different for different molal amounts of $\mathrm{LiCl}(0.5 \mathrm{M}, 1 \mathrm{M}, 3 \mathrm{M})$ (Supporting Information Figure S1 a-b). When the concentration is raised to $3 \mathrm{M}$, the overpotential does not decrease any further compared to the one with $2 \mathrm{M} \mathrm{LiCl}$, in contrast, begins to increase over time (Supporting Information Figure S1c). To uncover the influence of $\mathrm{Zn}$ dendrites growth by different anions, commonly used lithium salts, i.e. $\mathrm{Li}_{2} \mathrm{SO}_{4}$ and $\mathrm{LiNO}_{3}$, were also added as electrolyte additives. In contrast to the $\mathrm{LiCl}$ case, when adding a various amount of $\mathrm{Li}_{2} \mathrm{SO}_{4}$ or $2 \mathrm{M} \mathrm{LiNO}_{3}$ to the electrolyte, the overpotential of the redox reaction did not decrease and the stability dropped notably (Supporting Information Figure S2, S3). The same process was repeated under different current density (Supporting Information Figure S4, S5). When the current density increased to $2 \mathrm{~mA} \mathrm{~cm}^{-2}$, the overpotential of $\mathrm{Zn}$ deposition with additives remain in the lowest and the cycling process is quite stable We also tried current density of $1.5 \mathrm{~mA} \mathrm{~cm}{ }^{-2}$ and $5 \mathrm{~mA} \mathrm{~cm}{ }^{-2}$ using $3 \mathrm{M}$ ZnSO4 and 2M LiCl as electrolyte. ( Supporting Information Figure S6) Cycling process is stable under $1.5 \mathrm{~mA} \mathrm{~cm}^{-2}$ with additives. When current density increased to $5 \mathrm{~mA} \mathrm{~cm}^{-2}, \mathrm{Zn}$ plating/stripping still has relatively low overpotential, but the curve shows some fluctuations. We also carried out the cycling performance under $1 \mathrm{mAh} / \mathrm{cm}^{2}$ (current density of $1 \mathrm{~mA} / \mathrm{cm}^{2}$ ). The charge/ discharge process of the battery 
with additives remains highly reversible and the voltage is steady with a cycling life over 100 hours (Supporting Information Figure S7).

The morphological evolution of the zinc surface in pure $3 \mathrm{M} \mathrm{ZnSO}_{4}$ and $3 \mathrm{M} \mathrm{ZnSO}_{4} / 2 \mathrm{M} \mathrm{LiCl}_{\text {electrolytes }}$ after 500 cycles were examined by scanning electron microscopy (SEM). As indicated in Figure 1b, the zinc anode cycled in the $3 \mathrm{M} \mathrm{ZnSO}_{4} / 2 \mathrm{M} \mathrm{LiCl}$ electrolyte preserves a smooth surface. Higher magnification images (Figure 1c) show no obvious dendrite formation, indicating the successful suppression of dendrite growth. In sharp contrast, the zinc electrode cycled in the $3 \mathrm{M} \mathrm{ZnSO}_{4}$ electrolyte exhibited a mossy surface with petal-like Zn dendrites (Figure 1d, e). Besides, the morphology of the Zn electrodes in electrolytes with different concentrations of $\mathrm{LiCl}$ as additives was investigated (Supporting Information Figure S8). As the amount of $\mathrm{LiCl}$ increased, the size of the dendrites particles became smaller. When the concentration of $\mathrm{LiCl}$ was $2 \mathrm{M}$, it shows the best inhibitory effect. However, at a higher concentration of $3 \mathrm{M} \mathrm{LiCl}$, the dendrites grow more compact. This may because at the same values of
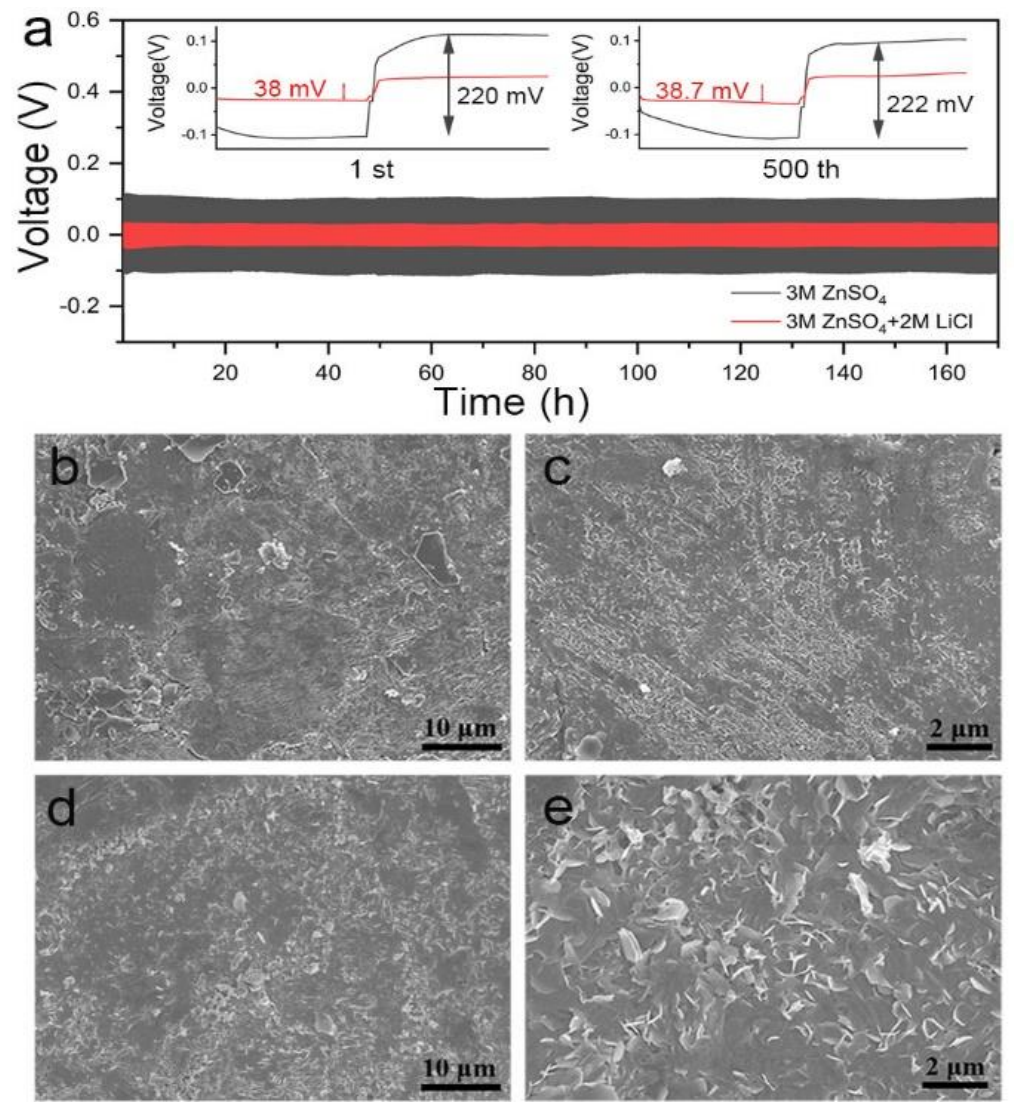

Figure 1. a) Galvanostatic charge/discharge curve under the current density of $0.2 \mathrm{~mA} / \mathrm{cm}^{-2}$ in different electrolytes. be) SEM of Zinc electrode surface after continuous charge/discharge process; b-c) $3 \mathrm{M} \mathrm{ZnSO}_{4} / 2 \mathrm{M} \mathrm{LiCl}$, d-e) $3 \mathrm{M} \mathrm{ZnSO}_{4}$. 
$\mathrm{ZnSO}_{4}$ concentration, though the conductivity increases (Supporting Information Figure S9), both the $\mathrm{pH}$ and liquidity decrease with the concentration increasing of $\mathrm{LiCl}$. It can lead to the uneven current distribution while the deposition of zinc, and thus influence the stability of $\mathrm{Zn}$ deposition/dissolution. ${ }^{42}$ SEM images (Supporting Information Figure S10) of the Zn surface after the same charge/discharge process with $2 \mathrm{M} \mathrm{Li}_{2} \mathrm{SO}_{4}$ as an additive show that the addition of $\mathrm{Li}_{2} \mathrm{SO}_{4}$ did not inhibit $\mathrm{Zn}$ dendrites, and the 'petals' appear larger. Similarly, adding $2 \mathrm{M} \mathrm{LiNO}_{3}$ into the electrolyte has a different morphology, but still allows the dendrites to grow on the $\mathrm{Zn}$ surface without inhibition. From these morphological results, we can infer that the anion $\left(\mathrm{Cl}^{-}\right)$plays a key role in inhibiting the growth of dendrites.

XRD patterns show the crystalline phases of the zinc electrode after continuous charge/discharge processes (Figure 2a). Dominant hexagonal Zn metal peaks can be seen in all the electrodes (PDF\# 040831). In addition, when running cycling test with $\mathrm{ZnSO}_{4}$, the $\mathrm{XRD}$ peaks on $\mathrm{Zn}$ surface at $21.1^{\circ}, 28.7^{\circ}$, $32.7^{\circ}$ and $33.8^{\circ}$ correspond to the phase of zinc sulfate hydroxide hydrate $\left(\mathrm{Zn}_{4} \mathrm{SO}_{4}(\mathrm{OH})_{6} \cdot 0.5 \mathrm{H}_{2} \mathrm{O}\right.$, PDF\#44-0674), ${ }^{43,44}$ (enlarged figure shown in Supporting Information Figure S11). While after adding $\mathrm{LiCl}$ as additives, the phase changed to $\mathrm{Zn}_{4} \mathrm{SO}_{4}(\mathrm{OH})_{6} \cdot 5 \mathrm{H}_{2} \mathrm{O}$ (PDF\# 39-0688). ${ }^{45}, 46$ This may because $\mathrm{LiCl}$ changed the $\mathrm{pH}$ value of the electrolyte, leading to different zinc sulfate hydroxide hydrate growth. What is more, with the increase of $\mathrm{LiCl}$ amount, the intense of major peaks at $16.2^{\circ}$ and $24.4^{\circ}$ became weak, indicating damage to the structure of ZHS. There are no obvious peaks of $\mathrm{ZnO}$ during the charging and discharging process.

The mechanism driving the suppression of $\mathrm{ZHS}$ and $\mathrm{ZnO}$ formation can be explained through the $\mathrm{pH}$ values of the different electrolytes (Figure 2b). The addition of $\mathrm{LiCl}$ makes the solution more acidic due to the polarizing effect of the lithium cation. As the amount of $\mathrm{LiCl}$ is increased, the $\mathrm{pH}$ value goes down. The pourbaix diagram of $\mathrm{ZnSO}_{4}-\mathrm{H}_{2} \mathrm{O}$ system at $25^{\circ} \mathrm{C}$ was calculated (Supporting Information Figure S12). ZHS and $\mathrm{ZnO}$ are not stable below $\mathrm{pH}$. When adding $\left(\mathrm{Cl}^{-}\right)$into the electrolyte, we get a mixture of $\left(\mathrm{ZnCl}_{4}{ }^{2-}\right)$ and $\left(\mathrm{ZnCl}_{3}^{-}\right)$which can lower the $\mathrm{pH}$ of the electrolyte and thus diminish the formation of ZHS and $\mathrm{ZnO}$. This acidic environment is therefore detrimental to the growth of the $\mathrm{Zn}$ dendrites. 
However, in a very acidic media, metallic $\mathrm{Zn}$ is not stable. As the $2 \mathrm{M} \mathrm{LiCl}$ additive produces a solution with suitable $\mathrm{pH}$ around the electrodes, this is close to the optimal value for inhibiting the growth of ZHS and $\mathrm{ZnO}$. As the $2 \mathrm{M} \mathrm{LiCl}$ additive produces a solution of $\mathrm{pH} 2.3$, this is likely close to the optimal value for inhibiting the growth of $\mathrm{Zn}$ by-products and dendrites during the cycling process. Though the $\mathrm{pH}$ is
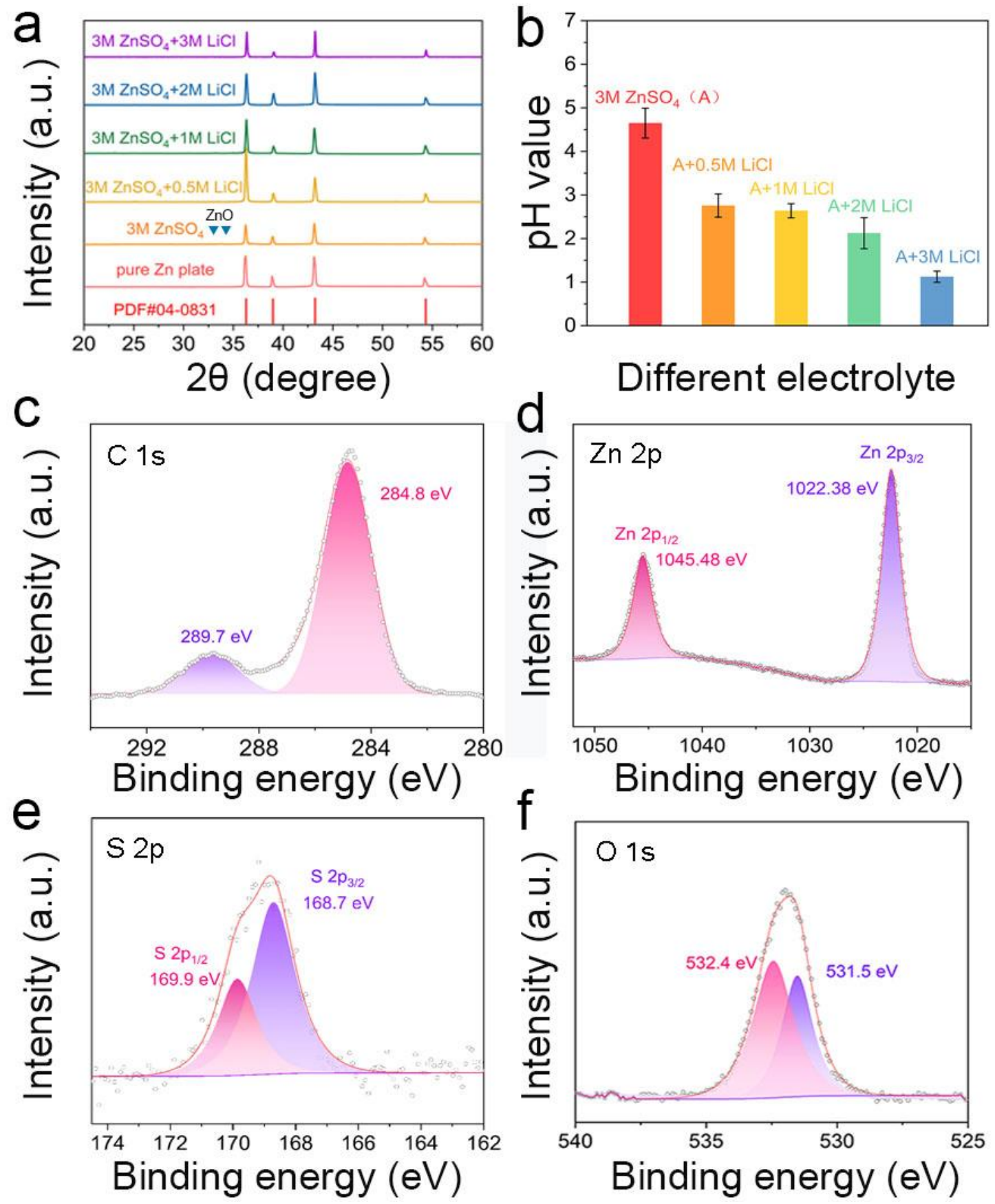

Figure 2. a) XRD of Zinc plate after charge/discharge with different electrolytes. b) $\mathrm{pH}$ value of different electrolytes. XPS spectra represented by patterns of different colors. (c) C 1s, (d) Zn 2p, (e) S 2p, and (f) O 1s of Zn surface after charge/discharge process with $2 \mathrm{M} \mathrm{LiCl}$ as the additive. 
relatively low, it has a stable working window when using commercial porous carbon or vanadium-based cathode materials in the following work.

To further determine the different surface functional groups present after cycling the Zn electrodes, XPS measurements were performed accordingly. Figure 2c-f shows the XPS spectra of the cycled (charge/discharge for 500 cycles at a current density of $0.2 \mathrm{~mA} \mathrm{~cm}^{-2}$ ) Zn electrode in the mixture of $3 \mathrm{M}$ $\mathrm{ZnSO}_{4}$ and $2 \mathrm{M} \mathrm{LiCl}$ electrolyte. The $\mathrm{C}$ 1s peaks of $\mathrm{Zn}$ surface was located at $284.8 \mathrm{eV}$, compared with C 1s peaks of Zn surface without additives (Figure S13), there is a new peak appears at $289.7 \mathrm{eV}$, which can be corresponded to $\mathrm{CO}_{3}{ }^{2-}{ }^{47}$ The $2 \mathrm{p}$ orbital of $\mathrm{Zn}$ (Figure $2 \mathrm{~d}$ ) is split into two peaks, located at 1022.38 $\mathrm{eV}$ and $1045.48 \mathrm{eV}$ respectively, corresponding to the $2 \mathrm{p}_{3 / 2}$ and $2 \mathrm{p}_{1 / 2}$ of $\mathrm{Zn}^{2+}{ }^{48}$ The peak positions of $\mathrm{S}$ $2 \mathrm{p}$ (Figure 2e) are located at $168.7 \mathrm{eV}$ and $169.9 \mathrm{eV}$ respectively, which can be assigned to the sulfate species ${ }^{48}$ such as ZHS, corresponding to the result of XRD. The O 1s (Figure 2f) spectrum has two peaks, here representing two distinct oxygen environments, which are located at $531.5 \mathrm{eV}$ and $532.4 \mathrm{eV}$, respectively. Although the peak at higher binding energy can be attributed to residual $\mathrm{ZnSO}_{4}{ }^{50}$, the other is due to the formation of $\mathrm{Li}_{2} \mathrm{O} / \mathrm{Li}_{2} \mathrm{CO}_{3}$, suggesting that these are the surface species formed in this electrolyte. ${ }^{51}$ We can therefore infer from the SEM and XPS data that when $2 \mathrm{M} \mathrm{LiCl}$ is utilized as an additive, $\mathrm{Li}_{2} \mathrm{O} / \mathrm{Li}_{2} \mathrm{CO}_{3}$ preferentially grows on the $\mathrm{Zn}$ surface, forming a non-conductive shielding layer and blocking the growth of $\mathrm{Zn}$ dendrites.

Supporting Information Figure S14, S15 show the XPS of the Zn surface after an equivalent number of charge/discharge cycles as above, but in $2 \mathrm{M} \mathrm{Li}_{2} \mathrm{SO}_{4}$ and $2 \mathrm{M} \mathrm{LiNO}_{3}$ with $3 \mathrm{M} \mathrm{ZnSO}_{4}$ respectively. When $\mathrm{LiNO}_{3}$ is used as an additive (Supporting Information Figure $\mathrm{S} 15 \mathrm{c}$ ), an N peak appears at $400.5 \mathrm{eV}(\mathrm{N}$ 1s) should be the $\mathrm{LiNO}_{3}$. This suggests that other less-beneficial side products are formed in this electrolyte, possibly $\mathrm{LiN}_{\mathrm{x}} \mathrm{O}_{\mathrm{y}}$ according to the peak position. ${ }^{52}$ Interestingly, $\mathrm{Li}_{2} \mathrm{O} / \mathrm{Li}_{2} \mathrm{CO}_{3}$ also appear to be formed, as shown by the presence of the $\mathrm{O} 1 \mathrm{~s}$ peaks at $531.4 \mathrm{eV}$. However, as no $\mathrm{Cl}^{-}$is present to unblock the surface, this results in greatly reduced cycling performance. Compared with other anions, the addition of $\mathrm{Li}^{+}$effectively inhibits the growth of $\mathrm{Zn}$ dendrites by forming a shielding layer of $\mathrm{Li}_{2} \mathrm{O} / \mathrm{Li}_{2} \mathrm{CO}_{3}$. 
After adding $\mathrm{Cl}^{-}$, it can encourage more pathways through the non-conductive layer of $\mathrm{Li}_{2} \mathrm{O} / \mathrm{Li}_{2} \mathrm{CO}_{3}$, increasing the ion transport, which is consistent with previous SEM results.

In addition, the layers are proved to be $\mathrm{Zn}^{2+}$ conductive by DFT simulations (Supporting Information Figure S16). Zn ions will diffuse along the [010] plane, lithium vacancy defects at low concentrations are inclined to distribute uniformly in bulk along the [010] plane, favourable for $\mathrm{Zn}$ ion diffusion in layers without bottleneck effect. More importantly, there should be a large potential variation across the protecting layer, due to its electrically insulating nature. As a result, only the potential near the $\mathrm{Zn}$ foil surface was low (or negative) enough for $\mathrm{Zn}^{2+}$ reduction, leading to a position-selected, bottom-up $\mathrm{Zn}$ deposition process, rather than preferential deposition on the tips of $\mathrm{Zn}$ protrusions/dendrites. ${ }^{53,54}$ The proposed schematic illustrations of $\mathrm{Zn}^{-}$plating on $\mathrm{Zn}$ foils was shown in Supporting Information Figure S17. As reaction went, the plated $\mathrm{Zn}$ formed a dense $\mathrm{Zn}$ microflake layer between the $\mathrm{Li}_{2} \mathrm{CO}_{3} / \mathrm{Li}_{2} \mathrm{O}$-layer and the residential $\mathrm{Zn}$ foil, which is also corresponding to SEM figure. This uniform bottom-up $\mathrm{Zn}$ deposition process avoided the development of large protrusions that may cause large polarization and cell shorting.

To better figure out the composition of the protective layer, we carried out Raman analysis on the surface of the $\mathrm{Zn}$ anode after $\mathrm{Zn} / / \mathrm{Zn}$ long cycling process under $0.5 \mathrm{mAh} / \mathrm{cm}^{2}$ (current density of $2 \mathrm{~mA} / \mathrm{cm}^{2}$ ). The data is shown in Figure S18. The peaks at 395, 451, 601, 965, $1005 \mathrm{~cm}^{-1}$ can be corresponded to $\mathrm{Zn}_{4} \mathrm{SO}_{4}(\mathrm{OH})_{6}{ }^{55}$ When the additives are added, the characteristic peak of ZHS is suppressed. Meanwhile, new peaks appear at the position of $528 \mathrm{~cm}^{-1}$ and $1093 \mathrm{~cm}^{-1}$ are characteristic peaks of $\mathrm{Li}_{2} \mathrm{O}$ and $\mathrm{Li}_{2} \mathrm{CO}_{3} .{ }^{56}$ The peak of $\mathrm{Li}_{2} \mathrm{CO}_{3}$ is quite weak, indicating the less amount of $\mathrm{Li}_{2} \mathrm{CO}_{3}$, it should be due to $\mathrm{CO}_{2}$ in the air dissolving in the electrolyte during cell assembling since we did not degas the electrolyte. We also performed SEM and energy-dispersive X-ray spectroscopy (EDS) mapping on the Zn surface after a long cycling process under the above conditions. SEM figures are shown in Figure S19 and SEM-EDS mapping results are shown in Figure S20 and S21. The protective layer can be seen from SEM images. Although it cannot show the signal of lithium directly, we can still get the information from the element 
change on the $\mathrm{Zn}$ surface with and without additives. The mapping figures show that there are $\mathrm{S}$ and $\mathrm{O}$ elements on the Zn surface without additives, indicating the growth of ZHS. On the contrary, after adding additives, $\mathrm{C}$ element appears instead of $\mathrm{S}$, meaning the growth of ZHS has been inhibited and $\mathrm{C}$ is from the $\mathrm{Li}_{2} \mathrm{CO}_{3}$. It can be proved that after adding $\mathrm{LiCl}$ as an electrolyte additive, a protective layer of $\mathrm{Li}_{2} \mathrm{O} / \mathrm{Li}_{2} \mathrm{CO}_{3}$ can be formed on the surface of the $\mathrm{Zn}$ anode. This conclusion is consistent with XPS and Raman data.

To further explore the growth process of dendrites on the surface of $\mathrm{Zn}$ under different electrolyte conditions, we performed in situ Electrochemical Atomic Force Microscopy (EC-AFM) measurements. A customized cell with a piece of $\mathrm{Zn}$ foil as the working electrode and another circle-shaped $\mathrm{Zn}$ foil as both reference and counter electrodes was used in chronoamperometry tests at a potential of $-0.2 \mathrm{~V}$. Figure 3 a-d' shows a series of AFM images of the zinc foil $(0.35 \mathrm{~mm})$ surface with pure $3 \mathrm{M} \mathrm{ZnSO}_{4}$ as
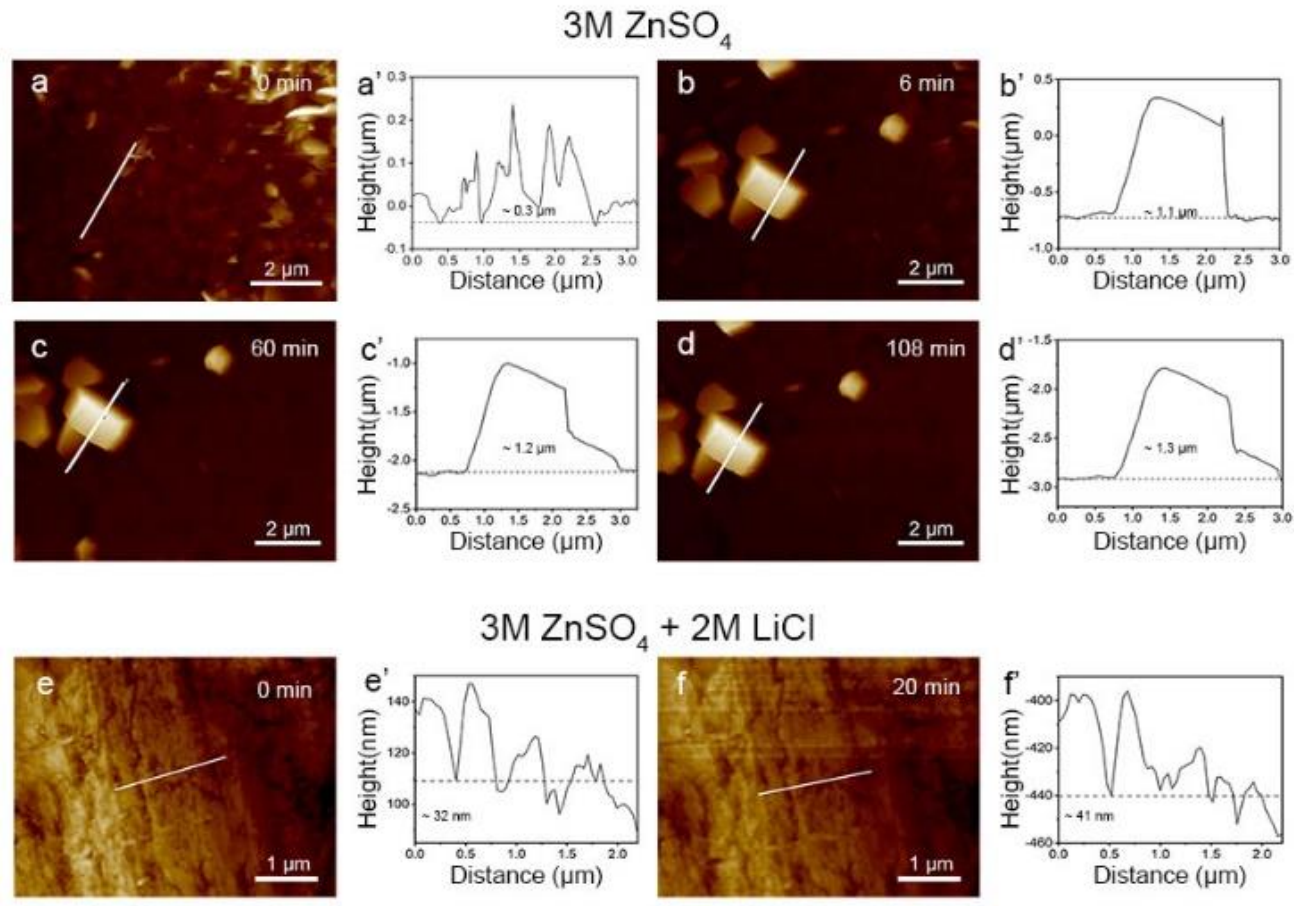

$$
\mathrm{O}_{4}+2 \mathrm{M} \mathrm{LiCl}
$$
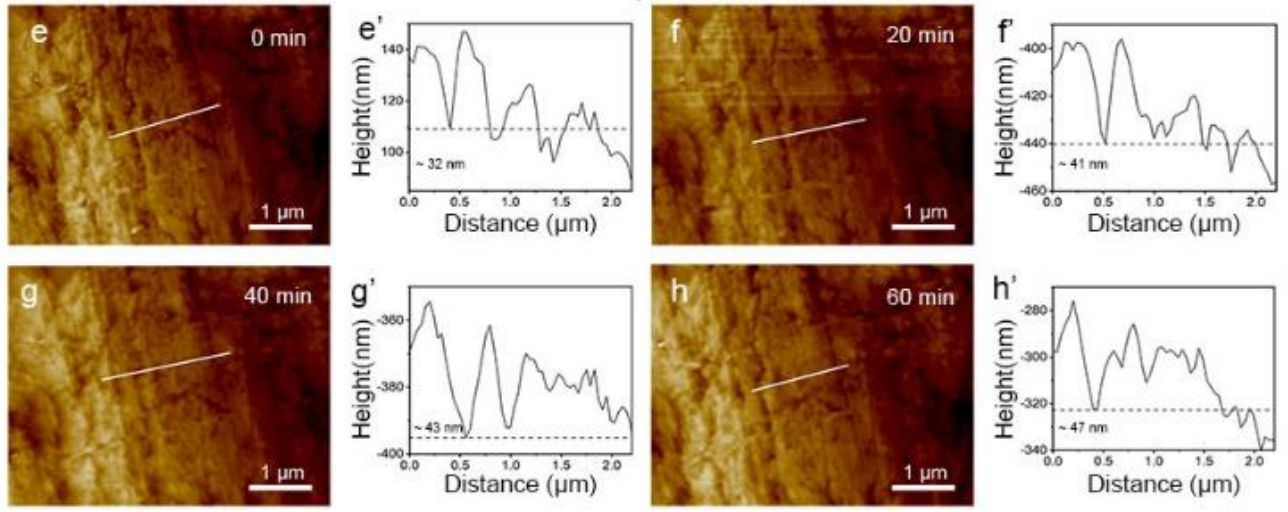

Figure 3. In situ AFM measurements of Zinc electrode surface in different electrolytes at various time periods under the constant potential of $-0.2 \mathrm{~V}$ vs. $\mathrm{Zn} / \mathrm{Zn}^{2+}$; a-d) $3 \mathrm{M} \mathrm{ZnSO}_{4}$, e-h) $3 \mathrm{M} \mathrm{ZnSO}_{4}$ and $2 \mathrm{M} \mathrm{LiCl}$. 
the electrolyte during the electrochemical process. Figure 3a shows that some petal-like structures form immediately once the $\mathrm{Zn}$ electrode is immersed in the electrolyte, of which the height is about $300 \mathrm{~nm}$. After holding the voltage at $-0.2 \mathrm{~V}$ for 6 mins, in addition to the petal structures, large particles grew as shown in Figure 3b. The marked line-scan shows that the cubic shaped particle is measured to have the highest point of $1.1 \mu \mathrm{m}$. Subsequently, the height measured from the large particle marked in the images gradually grows to $1.2 \mu \mathrm{m}$ and $1.3 \mu \mathrm{m}$, after the CA continues for 60 and 108 mins respectively. By contrast, the surface of the $\mathrm{Zn}$ electrode in the electrolyte with the addition of LiCl displays muchimproved stability of morphology during the same electrochemical process, as presented in Figure 3 e-h'. The smooth surface of the Zn electrode surface (Supporting Information Figure S22) is maintained when the electrolyte is added, and minimal roughness is observed (the highest point is around $32 \mathrm{~nm}$ ). The gradual increase of height is measured as $41 \mathrm{~nm}, 43 \mathrm{~nm}$ and $47 \mathrm{~nm}$ after the CA process is conducted for 20, 40 and 60 mins, respectively. It can be concluded that without electrolyte additives, large size $\mathrm{Zn}$ deposition particles form and grow fast during the plating process, while with the $2 \mathrm{M} \mathrm{LiCl}$ additive, the dendrites growth is suppressed and there is no evolution of the hydrogen, uniform $\mathrm{Zn}$ deposition is achieved. We also repeat the same process under a potential of $-0.15 \mathrm{~V}$ (Supporting Information Figure S23), which $\mathrm{LiCl}$ is still applicable.

Figure 4a shows the cyclic voltammetry $(\mathrm{CV})$ curves of the battery with pure $3 \mathrm{M} \mathrm{ZnSO}_{4}$ electrolyte. Figure $4 \mathrm{~b}$ shows the $\mathrm{CV}$ curves of the battery after adding $2 \mathrm{M} \mathrm{LiCl}$. Comparing two CV plots we can find in the absence of additives, a second peak is appearing, suggesting that some side reactions are happening. After the addition of $2 \mathrm{M} \mathrm{LiCl}$, the $\mathrm{CV}$ curves are very stable. From the second circle, the battery can be repetitively cycled to $100 \%$, and no other side reactions occur. At the same time, it is worth noting that after adding the additive, the $\mathrm{CV}$ curve area is larger, indicating that the battery has a higher capacity. According to the analysis result above, after adding $\mathrm{LiCl}$ additives, the protective layer formed on the $\mathrm{Zn}$ anode can efficiently keep $\mathrm{Zn}$ from other side reactions (growth of ZHS and corrosion), 
therefore $\mathrm{Zn}$ can realize a good stability during the cycling process, indicating a less capacity loss at meanwhile. ${ }^{57-59}$

Galvanostatic charge-discharge (GCD) profiles in Figure $\mathbf{S 2 4}$ show that the $\mathrm{Zn} / / \mathrm{C}$ cell exhibits typical capacitive behaviour. The specific capacitance of $\mathrm{Zn} / / \mathrm{C}$ cells is measured under different current densities with additives as the electrolyte. The red ball shows a measured capacitance of around $150 \mathrm{~F} / \mathrm{g}(40 \mathrm{mAh} / \mathrm{g})$ after adding $2 \mathrm{M} \mathrm{LiCl}$. We choose the commercial carbon material and it can be proved that after adding additives, $\mathrm{Zn}$ anode can still have good stability during charge/discharge process under different current densities. The Zn surface after rate process can be seen in Supporting Information Figure S25. Above shows that the $\mathrm{LiCl}$ additive increases $\mathrm{Zn}$ stability, consistent with the $\mathrm{CV}$ results.
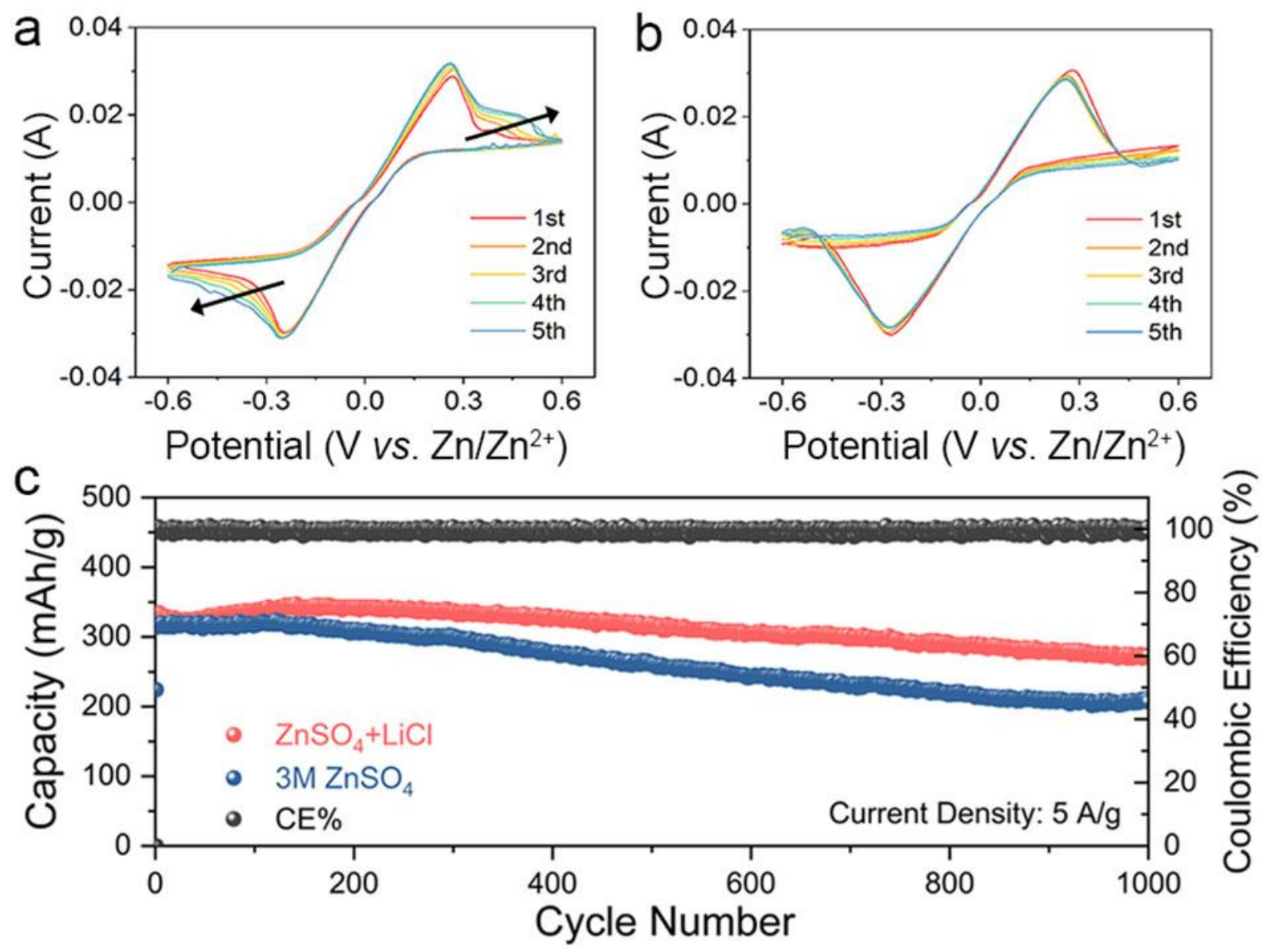

Figure 4. $\mathrm{CV}$ curves with different electrolytes a) $3 \mathrm{M} \mathrm{ZnSO}_{4}$; b) $3 \mathrm{M} \mathrm{ZnSO}_{4}$ and $2 \mathrm{M} \mathrm{LiCl}$ at first 5 cycles. c) Long cycling stability of $\mathrm{Zn} / \mathrm{O}_{\mathrm{d}}-\mathrm{NVO}$ cell in electrolytes with and without $\mathrm{LiCl}$ additive cells under a current density of 5 $\mathrm{A} / \mathrm{g}$. 
Finally, different electrolytes with oxygen vacancy rich- $\mathrm{NH}_{4} \mathrm{~V}_{4} \mathrm{O}_{10}\left(\mathrm{O}_{\mathrm{d}}-\mathrm{NVO}\right)$ as cathode were assembled for the battery performance in Swagelok cell configurations. Electrochemical Impedance Spectroscopy (EIS) measurements were carried out to investigate the influence of the $\mathrm{LiCl}$ additives on the inherent resistance of the system. Figure S26 shows the Nyquist plots of the $\mathrm{Zn} / / \mathrm{O}_{\mathrm{d}}-\mathrm{NVO}$ in $3 \mathrm{M} \mathrm{ZnSO}_{4}$ electrolytes with or without $2 \mathrm{M} \mathrm{LiCl}$. We can tell from the enlarged figure that the electrolyte with additives shows a lower inherent resistance ( 2 ohms $v s 6$ ohms), suggesting that the additives can help to improve the ionic conductivity. When adding $2 \mathrm{M} \mathrm{LiCl}$ into the electrolyte, it has higher conductivity, which agrees with the conclusion stated as above.

The GCD and rate performance was evaluated by a stepwise increase in current densities from 0.5 to 5 $\mathrm{A} / \mathrm{g}$ and returning to $0.5 \mathrm{~A} / \mathrm{g}$ with 10 cycles at each current density, respectively. Impressively, $\mathrm{Zn} / / \mathrm{O}_{\mathrm{d}^{-}}$ NVO exhibited superior rate capability in Figure $\mathbf{S 2 7}$ and reversibility with a capacity of $415 \mathrm{mAh} / \mathrm{g}$ at $0.5 \mathrm{~A} / \mathrm{g}$ in the initial first 10 cycles and $333 \mathrm{mAh} / \mathrm{g}$ at $5 \mathrm{~A} / \mathrm{g}$, which can be calculated as $80 \%$ of the initial capacity. Additionally, upon returning to $0.5 \mathrm{~A} / \mathrm{g}$, the capacity remains $380 \mathrm{mAh} / \mathrm{g}$, suggesting good reversibility. Cycling performance was evaluated under a different current density of $5 \mathrm{~A} \mathrm{~g}^{-1}$. The high reversibility with outstanding capacity retention, as shown in Figure 4c, was verified. Both electrolytes showed negligible capacity fading with a clear determination of a specific capacity of $272.1 \mathrm{mAh} \mathrm{g}^{-1}$ at the $1000^{\text {th }}$ cycle compared with $313.8 \mathrm{mAh} \mathrm{g}^{-1}$ at the $2^{\text {nd }}$ cycle for $\mathrm{LiCl}$ additive cells. Comparatively, 206.8 $\mathrm{mAh} \mathrm{g}^{-1}$ and $312.6 \mathrm{mAh} \mathrm{g}^{-1}$ was observed for the $1000^{\text {th }}$ cycle and $2^{\text {nd }}$ cycle, respectively, for cells without electrolyte additive. We also performed cycling performance under $0.5 \mathrm{~A} / \mathrm{g}$, as shown in Figure S28. Although there is no advantage in the capacity after adding $\mathrm{LiCl}$ additive, it has an obvious effect to stabilize batteries. During the charge/discharge process, the capacity of the battery without additives drops quickly. In contrast, the stability of the battery is improved after the additives are added, which corresponds to the previous conclusion. The above results imply that the electrolyte with LiCl additive possesses improved reversibility and superior specific capacity, which was observed under high current densities during the charge/discharge process. 
In summary, it was found that $2 \mathrm{M} \mathrm{LiCl}$ is an effective additive in aqueous $\mathrm{Zn}$ anode based batteries. The optimized electrolyte using $3 \mathrm{M} \mathrm{ZnSO}_{4}$ and $2 \mathrm{M} \mathrm{LiCl}$ can significantly inhibit the formation of dendrites on the surface of the $\mathrm{Zn}$ anode during continuous charge and discharge processes, which can greatly improve the cycling stability, reduce side reaction and increase overall capacity. When adding $\mathrm{Li}^{+}$to the electrolyte, a shielding layer of $\mathrm{Li}_{2} \mathrm{O} / \mathrm{Li}_{2} \mathrm{CO}_{3}$ formed on the zinc surface and this protection layer significantly inhibited the growth of $\mathrm{Zn}$ dendrites. By studying the electrolytes containing different anions, we can infer that the $\mathrm{Cl}^{-}$ions in the electrolyte play a key role in inhibiting $\mathrm{Zn}$ dendrites, which decrease the polarization and increasing the ion transport. This work highlights that the proper concentration of synergistic metal salts electrolyte is a promising strategy to solve dendrites problems and enhance the performance of zinc-ion-based aqueous batteries.

\section{Supporting Information}

The Supporting Information is available free of charge on the ACS Publications website at DOI: XXXX Detailed experimental procedures and chemical materials; cell cycling data, XRD, SEM images, XPS, Raman, EIS, and DFT simulations, CV curves, charge/discharge curves and rate performance (Figures $\mathrm{S} 1-\mathrm{S} 28)$ included in the SI

\section{Conflict of Interest}

The authors declare no conflict of interest.

\section{Acknowledgement}

We would like to thank China Scholarship Council and UCL Dean's prize for the joint Ph.D. studentship, Engineering and Physical Sciences Research Council (EPSRC, EP/L015862/1, EP/R023581/1), STFC Batteries Network (ST/R006873/1), RSC Mobility Grant (M19-7656) for funding support. National Natural Science Foundation of China (No. 51972223). We thank Mr. Changjun Cui, Mr. Yong Guo and Mr. Jiachen Gao at Tianjin University for help with the Raman, XPS and EDS measurement during revision. T.S.M thanks the EPSRC for support via his Fellowship EP/P023851/1. 


\section{References}

1. B. Dunn, H. Kamath and J.-M. Tarascon, Electrical energy storage for the grid: a battery of choices, Science (New York, N.Y.), 2011, 334, 928-935.

2. G. L. Soloveichik, Battery technologies for large-scale stationary energy storage, Annu. Rev. Chem. Biomol. Eng., 2011, 2, 503-527.

3. Q. Zhang, J. Luan, L. Fu, S. Wu, Y. Tang, X. Ji and H.-Y. Wang, Insights into Three-dimensional Dendrite-free Zinc Anode on Copper Mesh with Zinc-oriented Polyacrylamide Electrolyte Additive, Angew. Chem. Int. Ed., 2019, 58, 15841 .

4. J. F. Parker, C. N. Chervin, E. S. Nelson, D. R. Rolison and J. W. Long, Wiring zinc in three dimensions re-writes battery performance - Dendrite-free cycling, Energy Environ. Sci., 2014, 7, 1117.

5. H. Li, Z. Liu, G. Liang, Y. Huang, Y. Huang, M. Zhu, Z. Pei, Q. Xue, Z. Tang and Y. Wang, Waterproof and tailorable elastic rechargeable yarn zinc ion batteries by a cross-linked polyacrylamide electrolyte, ACS nano, 2018, 12, 31403148.

6. N. Zhang, F. Y. Cheng, J. X. Liu, L. B. Wang, X. H. Long, X. S. Liu, F. J. Li and J. Chen, Rechargeable aqueous zinc-manganese dioxide batteries with high energy and power densities, Nat. Commun., 2017, 8, 9.

7. F. Wang, O. Borodin, T. Gao, X. Fan, W. Sun, F. Han, A. Faraone, J. A. Dura, K. Xu and C. Wang, Highly reversible zinc metal anode for aqueous batteries, Nat. Mater., 2018, 17, 543-549.

8. C. Zhao, Q. Wang, Z. Yao, J. Wang, B. Sánchez-Lengeling, F. Ding, X. Qi, Y. Lu, X. Bai, B. Li, H. Li, A. AspuruGuzik, X. Huang, C. Delmas, M. Wagemaker, L. Chen and Y.-S. Hu, Rational design of layered oxide materials for sodium-ion batteries, Science (New York, N.Y.), 2020, 370, 708.

9. K. M. Diederichsen, E. J. McShane and B. D. McCloskey, Promising Routes to a High $\mathrm{Li}^{+}$Transference Number Electrolyte for Lithium Ion Batteries, ACS Energy Lett., 2017, 2, 2563-2575.

10. B. Li, Z. Nie, M. Vijayakumar, G. Li, J. Liu, V. Sprenkle and W. Wang, Ambipolar zinc-polyiodide electrolyte for a high-energy density aqueous redox flow battery, Nat. Commun., 2015, 6, 6303.

11. Q. Zhao, W. Huang, Z. Luo, L. Liu, Y. Lu, Y. Li, L. Li, J. Hu, H. Ma and J. Chen, High-capacity aqueous zinc batteries using sustainable quinone electrodes, Sci. Adv., 2018, 4, eaao1761.

12. M. Song, H. Tan, D. Chao, H. J. Fan, Recent Advances in Zn-Ion Batteries, Adv. Funct. Mater., $2018,28,1802564$.

13. C. Xu, B. Li, H. Du and F. Kang, Energetic Zinc Ion Chemistry: The Rechargeable Zinc Ion Battery, Angew. Chem. Int. Ed., 2012, 51, 933-935.

14. H. L. Pan, Y. Y. Shao, P. F. Yan, Y. W. Cheng, K. S. Han, Z. M. Nie, C. M. Wang, J. H. Yang, X. L. Li, P. Bhattacharya, K. T. Mueller and J. Liu, Reversible aqueous zinc/manganese oxide energy storage from conversion reactions, Nat. Energy, 2016, 1, 7.

15. Y. Yang, Y. Tang, G. Fang, L. Shan, J. Guo, W. Zhang, C. Wang, L. Wang, J. Zhou and S. Liang, Li ${ }^{+}$intercalated $\mathrm{V}_{2} \mathrm{O}_{5} \cdot \mathrm{nH}_{2} \mathrm{O}$ with enlarged layer spacing and fast ion diffusion as an aqueous zinc-ion battery cathode, Energy Environ. Sci., 2018, 11, 3157-3162.

16. S. J. Banik and R. Akolkar, Suppressing dendrite growth during zinc electrodeposition by PEG-200 additive, $J$. Electrochem. Soc., 2013, 160, D519-D523.

17. Z. Liu, T. Cui, G. Pulletikurthi, A. Lahiri, T. Carstens, M. Olschewski and F. Endres, Dendrite-Free Nanocrystalline Zinc Electrodeposition from an Ionic Liquid Containing Nickel Triflate for Rechargeable Zn-Based Batteries, Angew. Chem. Int. Ed., 2016, 55, 2889-2893.

18. M. Xu, D. Ivey, W. Qu and Z. Xie, Study of the mechanism for electrodeposition of dendrite-free zinc in an alkaline electrolyte modified with 1-ethyl-3-methylimidazolium dicyanamide, J. Power Sources, 2015, 274, 1249-1253.

19. O. Aaboubi, J. Douglade, X. Abenaqui, R. Boumedmed and J. VonHoff, Influence of tartaric acid on zinc electrodeposition from sulphate bath, Electrochim. Acta, 2011, 56, 7885-7889.

20. Z. Zhao, J. Zhao, Z. Hu, J. Li, J. Li, Y. Zhang, C. Wang and G. Cui, Long-life and deeply rechargeable aqueous Zn anodes enabled by a multifunctional brightener-inspired interphase, Energy Environ. Sci., 2019, 12, 1938-1949.

21. J. Huang, Z. Wang, M. Hou, X. Dong, Y. Liu, Y. Wang and Y. Xia, Polyaniline-intercalated manganese dioxide nanolayers as a high-performance cathode material for an aqueous zinc-ion battery, Nat. Commun., $2018,9,2906$.

22. S. S. Zhang, A review on the separators of liquid electrolyte Li-ion batteries, J. Power Sources, 2007, 164, $351-364$.

23. Z. Yuan, Y. Duan, T. Liu, H. Zhang and X. Li, Toward a Low-Cost Alkaline Zinc-Iron Flow Battery with a Polybenzimidazole Custom Membrane for Stationary Energy Storage, iScience, 2018, 3, 40-49.

24. L. Zhang, J. Cheng, Y.-s. Yang, Y.-h. Wen, X.-d. Wang and G.-p. Cao, Study of zinc electrodes for single flow zinc/nickel battery application, J. Power Sources, 2008, 179, 381-387.

25. H. Li, C. Han, Y. Huang, Y. Huang, M. Zhu, Z. Pei, Q. Xue, Z. Wang, Z. Liu and Z. Tang, An extremely safe and wearable solid-state zinc ion battery based on a hierarchical structured polymer electrolyte, Energy Environ. Sci., 2018, 11, 941-951. 
26. Y.S. Hu and Y. Lu, The Mystery of Electrolyte Concentration: From Superhigh to Ultralow, ACS Energy Lett., 2020, 5, 3633-3636.

27. S. Huang, J. Zhu, J. Tian and Z. Niu, Recent Progress in the Electrolytes of Aqueous Zinc-Ion Batteries, Chem. Eur. J., 2019, 25,14480-14494.

28. G. Fang, J. Zhou, A. Pan and S. Liang, Recent advances in aqueous zinc-ion batteries, ACS Energy Lett., 2018, 3, 2480-2501.

29. Q. Yang, G. Liang, Y. Guo, Z. Liu, B. Yan, D. Wang, Z. Huang, X. Li, J. Fan and C. Zhi, Do Zinc Dendrites Exist in Neutral Zinc Batteries: A Developed Electrohealing Strategy to In Situ Rescue In-Service Batteries, Adv. Mater., 2019, 31, 1903778.

30. P. Pei, K. Wang and Z. Ma, Technologies for extending zinc-air battery's cyclelife: A review, Appl. Energy, 2014, 128, 315-324.

31. Y. Li, M. Gong, Y. Liang, J. Feng, J.-E. Kim, H. Wang, G. Hong, B. Zhang and H. Dai, Advanced zinc-air batteries based on high-performance hybrid electrocatalysts, Nat. Commun., 2013, 4, 1805.

32. Y. Li and H. Dai, Recent advances in zinc-air batteries, Chem. Soc. Rev., 2014, 43, 5257-5275.

33. V. Soundharrajan, B. Sambandam, S. Kim, M. H. Alfaruqi, D. Y. Putro, J. Jo, S. Kim, V. Mathew, Y.-K. Sun and J. $\mathrm{Kim}, \mathrm{Na}_{2} \mathrm{~V}_{6} \mathrm{O}_{16} \cdot 3 \mathrm{H}_{2} \mathrm{O}$ barnesite nanorod: an open door to display a stable and high energy for aqueous rechargeable Zn-ion batteries as cathodes, Nano Lett., 2018, 18, 2402-2410.

34. B. Sambandam, V. Soundharrajan, S. Kim, M. H. Alfaruqi, J. Jo, S. Kim, V. Mathew, Y.-k. Sun and J. Kim, Aqueous rechargeable $\mathrm{Zn}$-ion batteries: An imperishable and high-energy $\mathrm{Zn}_{2} \mathrm{~V}_{2} \mathrm{O}_{7}$ nanowire cathode through intercalation regulation, J. Mater. Chem. A, 2018, 6, 3850-3856.

35. A. Bani Hashemi, G. Kasiri and F. La Mantia, The effect of polyethyleneimine as an electrolyte additive on zinc electrodeposition mechanism in aqueous zinc-ion batteries, Electrochim. Acta, 2017, 258, 703-708.

36. F. Wan, L. Zhang, X. Dai, X. Wang, Z. Niu and J. Chen, Aqueous rechargeable zinc/sodium vanadate batteries with enhanced performance from simultaneous insertion of dual carriers, Nat. Commun., 2018, 9, 1656.

37. W. Xu, K. Zhao, W. Huo, Y. Wang, G. Yao, X. Gu, H. Cheng, L. Mai, C. Hu and X. Wang, Diethyl ether as selfhealing electrolyte additive enabled long-life rechargeable aqueous zinc ion batteries, Nano Energy, 2019, 62, 275281.

38. A. Bayaguud, X. Luo, Y. Fu and C. Zhu, Cationic Surfactant-Type Electrolyte Additive Enables Three-Dimensional Dendrite-Free Zinc Anode for Stable Zinc-Ion Batteries, ACS Energy Lett., 2020, 5, 3012-3020.

39. K. Zhao, C. Wang, Y. Yu, M. Yan, Q. Wei, P. He, Y. Dong, Z. Zhang, X. Wang and L. Mai, Ultrathin Surface Coating Enables Stabilized Zinc Metal Anode, Adv. Mater. Interfaces, 2018, 5, 1800848.

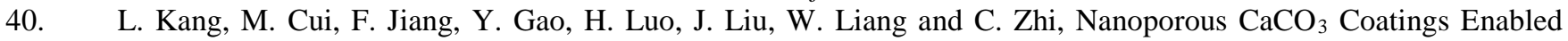
Uniform Zn Stripping/Plating for Long-Life Zinc Rechargeable Aqueous Batteries, Adv. Energy Mater., 2018, 8, 1801090.

41. D. Chao, C. R. Zhu, M. Song, P. Liang, X. Zhang, N. H. Tiep, H. Zhao, J. Wang, R. Wang, H. Zhang and H. J. Fan, A High-Rate and Stable Quasi-Solid-State Zinc-Ion Battery with Novel 2D Layered Zinc Orthovanadate Array, Adv. Mater., 2018, 30, e1803181.

42. B. Lee, H. R. Seo, H. R. Lee, C. S. Yoon, J. H. Kim, K. Y. Chung, B. W. Cho and S. H. Oh, Critical Role of pH Evolution of Electrolyte in the Reaction Mechanism for Rechargeable Zinc Batteries, ChemSusChem, 2016, 9, 29482956.

43. X.-Z. Zhai, J. Qu, S.-M. Hao, Y.-Q. Jing, W. Chang, J. Wang, W. Li, Y. Abdelkrim, H. Yuan and Z.-Z. Yu, Layered Birnessite Cathode with a Displacement/Intercalation Mechanism for High-Performance Aqueous Zinc-Ion Batteries, Nano-Micro Lett, 2020, 12, 56.

44. V. Soundharrajan, B. Sambandam, S. Kim, V. Mathew, J. Jo, S. Kim, J. Lee, S. Islam, K. Kim, Y.-K. Sun and J. Kim, Aqueous Magnesium Zinc Hybrid Battery: An Advanced High-Voltage and High-Energy $\mathrm{MgMn}_{2} \mathrm{O}_{4}$ Cathode, ACS Energy Lett., 2018, 3, 1998-2004.

45. Y. Huang, J. Mou, W. Liu, X. Wang, L. Dong, F. Kang and C. Xu, Novel Insights into Energy Storage Mechanism of Aqueous Rechargeable $\mathrm{Zn} / \mathrm{MnO} 2$ Batteries with Participation of $\mathrm{Mn}^{2+}$, Nano-Micro Lett, 2019, 11, 49.

46. F. Liu, Z. Chen, G. Fang, Z. Wang, Y. Cai, B. Tang, J. Zhou and S. Liang, $\mathrm{V}_{2} \mathrm{O}_{5}$ Nanospheres with Mixed Vanadium Valences as High Electrochemically Active Aqueous Zinc-Ion Battery Cathode, Nano-Micro Lett, 2019, $11,25$.

47. Wood, K. N.; Teeter, G., XPS on Li-Battery-Related Compounds: Analysis of Inorganic SEI Phases and a Methodology for Charge Correction. ACS Appl. Energy Mater. 2018, 1 (9), 4493-4504.

48. W. Zhang, S. Liang, G. Fang, Y. Yang and J. Zhou, Ultra-High Mass-Loading Cathode for Aqueous Zinc-Ion Battery Based on Graphene-Wrapped Aluminum Vanadate Nanobelts, Nano-Micro Lett, 2019, 11, 69.

49. X. Chang, X. Wu, Y. Guo, Y. Zhao, J. Zheng and X. Li, $\mathrm{SnSO}_{4}$ modified ZnO nanostructure for highly sensitive and selective formaldehyde detection, Sens. Actuators, B, 2018, 255, 1153-1159.

50. E. Andreoli, D. A. Rooney, W. Redington, R. Gunning and C. B. Breslin, Electrochemical Deposition of Hierarchical Micro/Nanostructures of Copper Hydroxysulfates on Polypyrrole-Polystyrene Sulfonate Films, J. Phys. Chem. C, 2011, 115, 8725-8734.

51. S. Tanaka, M. Taniguchi and H. Tanigawa, XPS and UPS studies on electronic structure of $\mathrm{Li}_{2} \mathrm{O}, \mathrm{J}$. Nucl. Mater., 
2000, 283-287, 1405-1408.

52. Y. Liu, D. Lin, Y. Li, G. Chen, A. Pei, O. Nix, Y. Li and Y. Cui, Solubility-mediated sustained release enabling nitrate additive in carbonate electrolytes for stable lithium metal anode, Nat. Commun., 2018, 9, 3656.

53. K. N. Wood, E. Kazyak, A. F. Chadwick, K.-H. Chen, J.-G. Zhang, K. Thornton and N. P. Dasgupta, Dendrites and Pits: Untangling the Complex Behavior of Lithium Metal Anodes through Operando Video Microscopy, ACS Cent. Sci., 2016, 2, 790-801.

54. J. W. Gallaway, D. Desai, A. Gaikwad, C. Corredor, S. Banerjee and D. Steingart, A Lateral Microfluidic Cell for Imaging Electrodeposited Zinc near the Shorting Condition, J. Electrochem. Soc., 2010, 157, A1279.

55. G. Falgayrac, S. Sobanska and C. Brémard, Raman diagnostic of the reactivity between $\mathrm{ZnSO}_{4}$ and $\mathrm{CaCO}_{3}$ particles in humid air relevant to heterogeneous zinc chemistry in atmosphere, Atmos. Environ., 2014, 85, 83-91.

56. F. S. Gittleson, K. P. C. Yao, D. G. Kwabi, S. Y. Sayed, W.-H. Ryu, Y. Shao-Horn and A. D. Taylor, Raman Spectroscopy in Lithium-Oxygen Battery Systems, ChemElectroChem, 2015, 2, 1446-1457.

57. H. J. Fan, Recent Advances in Zn-Ion Batteries, Adv. Funct. Mater, 2018, 28, 1802564.

58. D. Han, S. Wu, S. Zhang, Y. Deng, C. Cui, L. Zhang, Y. Long, H. Li, Y. Tao and Z. Weng, A Corrosion-Resistant and Dendrite-Free Zinc Metal Anode in Aqueous Systems, Small, 2020, 16, 29.

59. B. Tang, L. Shan, S. Liang and J. Zhou, Issues and opportunities facing aqueous zinc-ion batteries, Energy Environ. Sci., 2019, 12, 3288-3304. 
TABLE OF CONTENTS

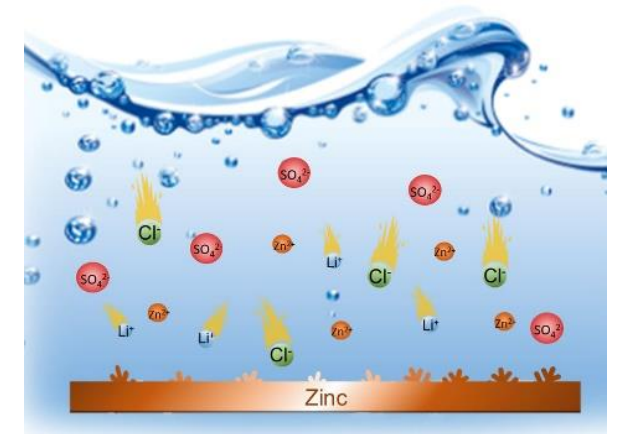

